LAW, ETHICS AND MEDICINE

\title{
The unfeasibility of requests for euthanasia in advance directives
}

\section{J J M van Delden}

J Med Ethics 2004;30:447-452. doi: 10.1136/ime.2002.002857

In April 2002 a new law regarding euthanasia came into effect in the Netherlands. This law holds that euthanasia remains a criminal offence unless it is (1) performed by a physician who (2) acts according to six specified rules of due care and (3) reports the case to a review committee. The six rules of due care are similar to those of the previous regulation and are largely based on jurisprudence. Completely new, however, is the article concerning a competent patient who has written an advance directive requesting euthanasia under certain circumstances. The law stipulates that a physician may act according to that written request, as long as he or she fulfils all other rules of due care. The author defends the view that these requests are neither feasible nor ethically justifiable, and presents both moral and practical arguments for this, claiming that for consistency reasons one cannot act on the basis of a written statement and fulfil the other rules of due care at the same time. The author also examines a difficult case of a demented, severely depressed woman who had written a living will requesting euthanasia before she became demented.

\footnotetext{
Correspondence to:

J J $M$ van Delden, Julius Center for Health Sciences and Primary care

University Medical Center, Utrecht, PO Box 85500 (HP D01.335), 3508 GA Utrecht, The Netherlands: j.j.m.vandelden@ umcutrecht.nl

Received

18 December 2002

Revised version received

21 February 2003

Accepted for publication

11 March 2003
}

I n April 2002 a new law regarding euthanasia and physician assisted suicide came into effect in the Netherlands. This law holds that euthanasia and assisted suicide remain criminal offences unless performed by a physician who acts according to six specified rules of due care and reports the case to an assessment committee. The six rules of due care are by and large the same as the ones of the previous regulation and are largely based on jurisprudence. They hold that:

- the physician must be convinced that the request of the patient was voluntary and well considered

- the physician must be convinced that the suffering of the patient was unbearable and without prospect of relief

- the patient must be informed about his/her situation and prospects

- the physician together with the patient must be convinced that there was no reasonable alternative solution for the situation

- at least one other physician must have seen the patient and must have given a written statement containing his evaluation of the four previous requirements

- the ending of life must be performed in a professional and careful way.

Not preceded by any jurisprudence, however, is article 2.2 of the law concerning an incompetent patient who has written, when he was still competent, an advance directive requesting the active ending of life under certain circumstances. The law stipulates that a physician may act according to that written request if the patient becomes incompetent, as long as she fulfils all other rules of due care in a corresponding way. This article will be the focus of this paper. The discussion of this type of regulation has relevance, I believe, for a wider audience then a Dutch one, because the underlying problems are certainly not typically Dutch.

I suppose one could argue against the tenability of it, following at least three lines of argument. One could hold that the addition of article 2.2 results in an inconsistent law, or that it is inconsistent with the basic normative structure of the Dutch euthanasia regulation. The stronger claim would be that it is ethically wrong to perform euthanasia on the basis of a written statement. I will begin by dealing with the first two inconsistency claims and will then concentrate on the latter.

Let me first sketch in a few lines the clinical situation that corresponds with this debate. Although, to my knowledge, no case has been presented to the assessment committees yet, one may assume that typical cases will involve demented patients, especially when they have become so demented that admittance to a nursing home is required. One may also assume that most written statements in these relevant cases will be standard documents as issued by the Dutch association for voluntary euthanasia (NVVE). These statements contain the request to perform euthanasia in cases of unbearable suffering. They allow the person who signs the statement to specify what he considers to be unbearable by ticking one or several boxes. Box D of the standard NVVE document mentions progressive cognitive impairment as one such possibility. It specifies that such impairment could imply that personal orientation as well as communication is lost, and institutionalisation has become necessary. By ticking this box, the person drawing up the statement requests euthanasia to be performed in such situations.

Abbreviation: NVVE, Dutch association for voluntary euthanasia. 
A final remark about the type of action. Contrary to many other countries, in the Netherlands euthanasia and physician assisted suicide are largely treated as two of a kind. That is why they are covered by the same law and assessed by the same committees. In cases of acting upon an advance directive, however, I suppose we only have to consider euthanasia. Given the incompetence of the patient, assisting in suicide will no longer be possible for "technical" reasons.

\section{INCONSISTENCY IN THE LAW}

When a physician acts upon a written request of a now incompetent patient and performs euthanasia, the law requires that she fulfils the same rules of due care as in "normal" cases of euthanasia involving competent patients. This, however, seems to me to be a requirement that is hard to fulfil. I will try to prove my point by examining the six criteria of the law that were specified in the introduction.

The first criterion states that the physician must be convinced that the request of the patient was voluntary and well considered. Normally this criterion implies that the request of the patient must have been rehearsed and that it must have been made without pressure from others. It will be difficult for the physician to get information about the decision making process that lead to the signing of the statement, perhaps years ago. How will she be able to know that it was a well considered request made without pressure from others? One could argue that this is shown by the mere fact that someone has taken the trouble of drawing up a statement in the first place. I think however that what this primarily shows is that the patient had strong beliefs, rather than that they were well considered or that the patient was well informed. And what about the repeated request? Of course one could point to the fact that often these advance directives are repeatedly signed, every year or so. But this hardly suffices: the repeating of a conditional request ("if I become demented, I want you to kill me") does not amount to the same thing as the repeating of an actual, unconditional request ("I want you to kill me now, because I have become demented"). People adapt to new situations and experience often differs from expectation.

The second criterion holds that the physician must be convinced that the suffering of the patient was unbearable and without prospect of relief. There are at least two problems here. The first is that it is not clear when the physician can be convinced that the patient suffers unbearably. In "normal" cases of euthanasia, this is something that the patient will tell her. He will explain and give reasons why the suffering has become intolerable. The essence of this is the communication between patient and physician. It is precisely this that has become difficult, if not impossible (compare with the text of box D of the NVVE statement!). This leaves the physician with nothing more than the old assessment by the patient of a then hypothetical situation without much insight in the actual present assessment. The second problem concerns the clause "no prospect of relief". Normally, what is meant by this is not that the underlying disease is incurable, but that the symptoms (pain, distress, nausea, vomiting, itching, and so on) cannot be relieved. In line with this, a diagnosis of a dementia syndrome alone cannot be enough. The associated distress, disorientation, or emotional instability could be enough, but these are often relieved-at least to some extent-by the admission to a nursing home, which provides structure and protection to the demented patient.

I now turn to the third criterion: "the patient must be informed about his/her situation and prospects". Let me recall that the specification in the box of the NVVE statement describes a patient who has lost much of his ability to communicate. By definition, then, it will be impossible for the present physician to do what this criterion demands. But that is too easy, one could object. The criterion should be understood as to mean that the person should have been informed about his situation and prospect at the time of the writing of the statement. The obvious problem however, is that the proportion of (mis)fortune telling in most medical curricula is far too little for a physician to be able to do this. Even in cases of genetically determined dementias, it is not certain that the actual experience of the future patient will be the same as in the witnessed case of a close relative. Moreover, in reality there are many feasibility problems here. A patient need not consult a physician at the time of writing an advance directive. And even if he does, that physician need not do more than just store it in the patient's file. Finally, in many cases the physician of the now incompetent patient who is confronted (by family members for instance) with the advance directive will not be the same person as the treating physician when the document was written. It follows that in many cases it will be hard for the present physician to know whether or not the patient was adequately informed.

The problems with the fourth criterion are to some extent already mentioned. The criterion reads: "the physician together with the patient must be convinced that there was no reasonable alternative solution for the situation". This of course requires a form of communication that will no longer be possible with the now incompetent patient. The rejoinder that such communication should have been done when the patient was still competent fails, because at that time it would have been hard to predict what symptoms will dominate the clinical situation later on.

The law requires in all cases that at least one other physician must have seen the patient and must have given a written statement containing his evaluation of the four previous requirements. This fifth rule, at first glance, may seem easy to fulfil: a consulting physician can as easily visit an incompetent patient as a competent one. But if one considers the situation a bit longer, one will see many problems. For what else can this second physician do but confirm that there is an advance directive and that the patient involved is incompetent. He cannot communicate with the patient any better than the treating physician can. Yet he has to assess all four criteria mentioned above. While trying to do so, he will run into the same problems as I described for each of them.

The final requirement of the law states that the ending of life must be performed in a professional and careful way. Normally, when assessing a "normal" case with respect to this criterion, an assessment committee will review the drugs used (for example, physicians should not use muscle relaxants without proper deep sedation) and check whether the physician was present during the ending of life. If one takes this to be the content of this criterion, then finally this is one the physician can comply with even in the case of an incompetent patient.

Behind these specific problems that I have described, one serious objection to the whole line of argument remains. The text in article 2.2 of the euthanasia law does not read that the physician should follow the six rules of due care in the exact same way as in "normal" euthanasia cases. Instead it asks for fulfilment of the other rules of due care in a corresponding way (in Dutch: overeenkomstige toepassing). This means that the law allows for some adjustment of the rules to the specific circumstances of the case. Would this not be the key to the solution of all problems I have described?

I hardly think so. Let us briefly examine a well known example: the way information is provided when informed consent to research is sought. It is usually accepted that this information is presented in a way that corresponds with the 
level of understanding of the subjects. Too much, too detailed, too technical information only hampers the decision making process. At the same time, however, this surely does not mean that one can do without informing at all. As I described above, the problems for the physician who tries to act according to the rules in the case of an incompetent patient's written request for euthanasia are manifold. Moreover, that which results is not just a gradual departure from the rules; the problems affect the very heart of the regulation. "To act in a corresponding way" means to allow for some interpretation of the rules, not to open the possibility of ignoring them altogether. Therefore, I do not think the "corresponding way" clause is able to save the consistency of the law.

\section{INCONSISTENT WITH CURRENT MORAL FRAMEWORK}

There would seem to be three ways of dealing with the issue of euthanasia. ${ }^{1}$ The first is to reject it on the grounds that it is forbidden by the principle of respect for life. Proponents of this view reject the idea that life can ever be ended prematurely. They often add the claim that euthanasia is not necessary at all. With sincere attention for the person who requests euthanasia the "question behind the question" will surely turn out to be something other than a request for dying and, with good palliative care, extreme suffering need not remain unanswered. In this view euthanasia and palliative care are incompatible: less euthanasia will result from better palliative care. ${ }^{2}$

An alternative response to the euthanasia issue stresses the importance of compassion. From this point of view, respect for life is of paramount importance, as is good palliative care. Sometimes however, supporters of this view admit that illness and dying come with such suffering that life is reduced to pointless surviving. If all other palliative measures fail, then euthanasia may be justified. The result of this view on euthanasia is the medicalisation of the end of life, because whether or not euthanasia is justifiable becomes largely a matter of medical discretion. These two responses appear to differ foremost in their answer to the question "Does intractable excruciating suffering exist?" However, even palliative care specialists will state that, unfortunately, this is true. As pain has important emotional and psychological as well as sensory components, and as dying is often simply tragic, it seems inevitable that suffering and dying will forever be linked. The real difference therefore, will be whether or not one allows the principle of respect for life to be overridden by other considerations in special circumstances or not.

A third approach emphasises respect for patient autonomy in which euthanasia is seen as a choice. Some patients do vnot want to live through suffering and decline, even if pain can be controlled. They want to autonomously decide about how and when to die and want their relatives to remember them as they were when they were more or less healthy. They want to step out of life before the terminal phase really starts and they want a doctor to do the lethal work.

Most proposals to regulate euthanasia follow the Dutch example and take the second view. ${ }^{3}$ The second and fourth requirement of the Dutch law on euthanasia, which I described above, clearly create room for an independent, professional evaluation of the situation by the physician. What follows is that under this law there is no right to die in the Netherlands, nor an obligation for the physician to comply with the request of a competent patient if certain conditions are met. In moral terms: euthanasia by a physician can never be exclusively based on respect for patient autonomy. A physician is not in the service of the patient's self determination, he has his own job to do of serving the patient's wellbeing. It may be the case that the patient's suffering can only be ended by ending his life. But in that case the physician's motive is compassion, not respect for autonomy. If this is true-and I think it is-the physician should form an independent, professional judgement that the patient is right in considering his suffering hopeless and unbearable.

By describing the moral framework for euthanasia and assisted suicide in the Netherlands, I obviously want to make a point in our debate concerning advance directives. I think this short description draws the eye to another consistency problem. As I said before, the euthanasia practice in the Netherlands is largely medicalised and therefore I think that the basic moral framework for the Dutch euthanasia law is the second view that I have described above. The essential part of that view is the independent role of the physician as a moral actor; not merely as a fact provider. ${ }^{4}$

The addition of article 2.2 introduces elements of the third, autonomy driven approach. The background idea of this article is the rational autonomous subject who decides about his death and about the way he does (or does not!) want to live. As one characteristic of the life he does not want to live is being incompetent, he has to write an advance directive while still competent.

It is precisely the incompatibility of these two views that lies behind all the problems I have described in the previous section. The compassion driven framework obligates the physician to form his own opinion and judgement in communication with the patient. The autonomy driven framework however, is hardly interested in these things. As long as the patient was really autonomous when writing the advance directive, the physician can comply with the written request. In this line of thinking, it is only in the realisation of this request that medical skills are asked for. This is another reason why I do not think a physician can comply with the six requirements as well as perform euthanasia upon the written request of an incompetent patient.

\section{ETHICAL PROBLEMS}

Advance directives protect autonomy interests of the now incompetent person. They do so by promoting a previous wish into an actual one, thus ignoring the time interval between the two. Irrespective of the specific content of such directives, two sets of ethical problems are inherent in them. The first concerns problems of wording: because in reality the person writing the advance directive does not know (at least not exactly) what the future will bring, he will describe situations in which the directive should be applied in broad terms. This can easily lead to interpretation problems (what exactly are "extraordinary means"?, when exactly can one say that a demented person has lost recognition of his family: when he fails to recall their names, or when his behaviour no longer shows that he is familiar with them?). More carefully worded documents can help a bit, but not enough: as soon as one becomes more specific, the document looses sensitivity, thus also missing the purpose of the whole enterprise. If one would for instance try to describe exactly in what cognitive state the advance directive should be activated ("with the loss of recognition of proxies I mean that I no longer can retrieve the names of my children"), the patient runs the risk that the directive is activated much later than he would wish if he happens to get to suffer from vascular dementia instead of Alzheimer's dementia.

The second inherent ethical problem of advance directives has to do with the continuity of the person. Normally, people have an impressive potential to adapt to new situations. They often find ways to come to terms with situations they would 
have thought to be unbearable before. Incompetent people seem to have lost this potential, or to be more precise: they have lost the ability to reflect upon their situation and describe whether or not they have come to terms with it. At this point it becomes crucial to notice that the demented patients we are concerned with here, although incompetent, differ very much from (for example) permanent vegetative state patients, in that they are much more present than vegetative patients. They still have wishes, form opinions, have fears or preferences, and are still able to value thingshowever deficient from a cognitive point of view these might be. If the evaluations of a demented person do not coincide with those of the previous person who wrote the advance directive, whose wishes should have priority: those of the previous or of the present person? I should hasten to add that from the observations mentioned above, I do not infer a new threshold for personhood, as Jaworska seems to do. ${ }^{5}$ Like Beauchamp, ${ }^{6}$ I would like to diminish the importance of the concept of personhood in determining the moral status of people. Demented people deserve moral status whether they fulfil criteria for personhood or not.

These inherent problems of advance directives give rise to at least two questions. The first is: should we accept advance directives as an instrument to determine what the wish of an incompetent person would be? Some think we should, ${ }^{7}$ others question this. ${ }^{8}$ I will not elaborate on this first question here, because it deserves a separate paper. Instead I will concentrate on a second question. In order to do so, I will assume that there are two sorts of advance directives: negative ones, containing a treatment refusal, and positive ones, containing a wish that something be donefor example, the termination of life. My question is: is there a morally relevant difference between these sorts of advance directives? I think there is and by providing reasons for this I hope to show that, irrespective of the value of negative directives, positive ones are "a bridge too far". 9

I will start by pointing to different elements in the right to autonomy. It is one thing to be free from controlling influences by others and from limitations that prevent choice. It is something else to be able to act in accordance with a self chosen plan. These different elements correspond with different obligations of others. In its negative form the obligation to respect autonomy calls for respecting individuals' views as long as they do not harm others. The positive form of respecting patient autonomy implies fostering autonomous decision making. It does not imply that someone else is obligated to act according to your wishes. Moreover, when someone else is asked to act we shall have to allow her a certain room for free choice, at least if we want that person to take responsibility for her actions. Therefore I think people have more reason to refrain from action according to the negative claim than to act according to the positive one.

Ethicists who are not convinced by anything that is put forward in terms of rights may be more convinced by a closer look at the concept of autonomy itself. ${ }^{10}$ I think this is indispensable if we want to extend autonomy into precedent autonomy, which is what we do when we act upon advance directives. What exactly is autonomy? Autonomy could be explained as sovereignty. In this view of autonomy, autonomous people are reasonable people who can reflect on a situation, can question what seems to be evident, can deliberate, and then choose. I think it is evident that this interpretation of autonomy cannot support the extension of autonomy into precedent autonomy. At the moment precedent autonomy is invoked, the patient involved will no longer be able to deliberate or choose. As soon as the advance directive becomes relevant, it is this directive that determines what needs to be done, not the patient.
An alternative view on autonomy stresses the importance of being what you want to be, of "writing your own biography"; of expressing one's identity. In this view authenticity is the key concept. For the present discussion it is crucial to see that the wish to be yourself and live in accordance with you own identity is less dependent on actual expressed wishes. Authentic desires in a certain way survive the incompetent patient. Therefore I think autonomy, taken as authenticity, can provide a basis for precedent autonomy. This would mean that we should view advance directives as indications of what would fit the biography of the patient mostly. We cannot, however, infer from them a sovereign choice that is able to change the physician's line of action from normal medical care into termination of life.

If I am correct so far, this would mean that the strength of advance directives changes with the type of claim they contain. To ask not to be treated in certain circumstances is the more powerful claim; strong enough, I submit, to overcome the inherent problems. To ask to be treated in a certain way (in this case to be put to death) is the weaker claim-certainly not strong enough to be the sole reason for a physician to perform euthanasia. For that she would surely need reasons of her own, which brings us back at all the problems I discussed in the first paragraphs of this paper.

\section{A HARD CASE}

It may be that I am biased. Perhaps I have made it too easy for myself and used examples that served my rhetorical purposes better than that they proved my point. So let me make it more difficult and examine a truly hard case.

In the nursing home I work in, a demented lady was admitted. She suffered from Alzheimer's disease, was a widow of 84 years of age and had one son who visited her regularly. Some years before entering the nursing home she had become a member of the NVVE after experiencing the cognitive decline of her husband. She had also, after deliberations with her son, signed an advance directive in which her wish for euthanasia under certain circumstances was explicitly stated. She had ticked box D in section 9 indicating that she included dementia in her interpretation of a situation of unbearable suffering.

One year after admittance it had become clear that the physicians treating her were not successful in controlling her depression. Psychological interventions had proved unsuccessful. She also had used several (classical and modern) antidepressants in sufficient dosages and over sufficient periods to leave little hope for any success in the future. The consequence was that she was walking up and down the ward all day with a sad face, sometimes silently weeping, sometimes approaching staff for help. We would also find her complaining to her mirror image (which she did not recognise as her own face) or trying to call her son, whose telephone number she had forgotten.

During a regular meeting between her son and the staff, her son reminded us of the advance directive and asked what we should do with her wish. What indeed?

I think this example shows that in some cases some of the problems I have mentioned can be overcome. Her treating physician in this case was able to get an impression of the decision making process before signing the advance directive, through her son. Her son could also explain what she meant by certain terms. Also, the distress caused by her dementia had proved to be irremediable. This is true both from the patient's perspective as well as from the physician's.

Other problems, however, remain. The most one can get is the rehearsal of a conditional request, not an actual one. As it 
is still impossible to communicate in a reasonable way with the patient herself, it remains hard to know what she wants now. It is precisely this lack of communication that forms the heart of the problem in this case. I think the decision making process usually involved in a "normal" euthanasia case entails more than just the addition of one voluntary, well considered wish to one professional evaluation of the situation as hopeless. It is through a communicative process that both elements - a wish and a professional evaluationbecome a shared intention to act. It is in this vital process that compassion arises, and it is precisely this vital process that is per definition missing in the case I have described. It is as if one has to prepare a meal by mixing ingredients, but without cooking them.

There is another problem, not mentioned before, that remains. I think it is truly unfeasible, from a practical point of view, to perform euthanasia in such cases. Imagine for a moment what this would mean. Suppose that after a thorough discussion the physician and her son decide that they should follow the advance directive, what exactly should they do? Ask the patient to follow them, insert a needle, and inject the lethal drug? This would certainly cause a lot of stress to the patient, which is exactly what they want to prevent. First sedate her and then perform euthanasia? I think these are unimaginable actions. And I suspect that this is so because the reason to act lies mostly in the past, not in the present.

\section{CONCLUSION}

I hope to have shown that a regulation for performing euthanasia on an incompetent patient on the grounds of that person's previously written advance directive is a mistake. It creates inconsistencies both within the law (if present) and with the moral framework that is mostly behind such regulation. Moreover, the claim of such a directive is not strong enough to counterbalance the inherent ethical problems of advance directives. From a practical point of view there is a serious lack of a communicative process. I conclude, therefore, that advance directives containing a written request for euthanasia are unfeasible and that it is not ethically justifiable to act upon them.

\section{REFERENCES}

1 van Delden JJM. Slippery slopes in flat countries. J Med Ethics 1999;25:22-4

2 Twycross RG. Where there is hope, there is life: a view from the hospice. In: Keown J, ed. Euthanasia examined. Cambridge: Cambridge University Press, 1995.

3 Brazier M. Euthanasia and the law. Br Med Bulletin 1996;52:317-25.

4 Savalescu J. Rational non-interventional paternalism: why doctors ought to make decisions on behalf of their patients. J Med Ethics 1995;21:327-31.

5 Jaworska A. Respecting the margins of agency: Alzheimer's patients and the capacity to value. Philos Public Aff 1999;28:105-38.

6 Beauchamp T. The failure of theories of personhood. Kennedy Inst Ethics J 1999;9:309-24.

7 Dworkin R. Life's dominion. London: Harper Collin Publishers, 1993.

8 May T. Slavery, commitment, and choice: do advance directives reflect autonomy? Camb Q Healthc Ethics 1999:8:358-63.

9 Which, by the way, was a Dutch bridge (in Arnhem).

10 Delaere P. Tussen iemand en niemand. In: Willigenburg Th, Gevers S, Varekamp I, Delaere P, eds. Zelfbinding in de psychiatrie. Rotterdam: Erasmus University, 2002.

\section{COMMENTARY}

It may be helpful for readers to know how advance directives and withdrawal of treatment decisions operate in the UK. It is now categorically laid down in law that a competently delivered refusal of treatment-either current or advancedmust be respected, even if this leads to the death of the patient. This was confirmed in 2002 in the case of Ms B, where the hospital authorities were ordered to pay $£ 100$ in damages for assault for continuing to ventilate Ms B against her wishes. It should be stressed, however, that the jurisprudence to date has focused on refusals of treatment and has not endorsed the legality of requests that a patient's life be ended through active intervention. The active/passive distinction is, of course, as controversial for the law as it is for ethical discourse, but the courts repeatedly make the point that active euthanasia remains illegal in the UK.

This having been said, the medicalisation of decisions to withhold or to withdraw treatment has held considerable sway, and for many, such a decision that results in the death of the patient is tantamount to (passive) euthanasia. In the context of incompetent patients, for example, the courts have confirmed the legality of this approach in a virtually unqualified way. They have done so in the context of withdrawal of artificial nutrition and hydration from patients in persistent vegetative state (PVS). ${ }^{2}$ The obligation is to treat incompetent patients in their own best interests, but this has been interpreted to mean that so long as there is a good faith medical assessment of the futility of continuing with the "treatment" then it will be legal to withdraw it. This has been subject only to the need to obtain a declaration from a court, which in practice has represented little more than a rubberstamping of the medical diagnosis of PVS.

The British Medical Association generated controversy by suggesting that this legal authority might be extended to legitimate the withdrawal of the same "treatment" from patients with severe dementia or those who have suffered catastrophic stroke. ${ }^{3}$ The difference, of course, between these patients and patients in PVS is that the latter are insensate whereas the former are not. Notwithstanding, the General Medical Council (GMC), for its part, produced guidelines in 2002 entitled Withholding and Withdrawing Life-prolonging Treatments: Good Practice in Decision-making, which similarly envisaged withdrawal or withholding of artificial nutrition and hydration from sensate patients.

Most recently, however, the English High Court has challenged the legality of the GMC guidelines in a ruling which champions the right of self-determination of patients. ${ }^{4}$ In holding that patients have a human right to choose how to pass their closing days and moments of their life and how to manage their death, the Court held that medical assessments of futility cannot be determinative when dealing with competent patients: "If the patient [is] competent (or, although incompetent, [has] made a valid and relevant advance directive) his decision as to where his best interests [lie] and as to what life-prolonging treatment he should or should not have [is] in principle determinative". But this, it should be noted, was in the context of a patient suffering from a progressive degenerative disorder which would, ultimately, require artificial nutrition and hydration. The concern was not that a refusal would not be respected, but that the decision would be taken out of the patient's control. The ruling confirms that that control remains firmly with the patient. It is, however, subject to one important caveat. This is the 2002 decision of the European Court of Human Rights in Pretty $v$ UK where it was confirmed that the UK was not in breach of its international human rights obligations by not providing legal means by which patients could request assistance in dying. ${ }^{5}$ Although the Court acknowledges the importance of respecting patients' wishes in treatment decisions and maintaining their dignity as far as possible, this did not extend to a right to assisted suicide, nor, a fortiori, euthanasia.

Thus, the position in the United Kingdom is that competent patients have an absolute right to refuse medical treatment even if death is the result, and a right to judicial 
review of withdrawal or withholding decisions with which they disagree, but there is no right to demand respect for requests for active euthanasia, expressed in advanced directives or otherwise.

G Laurie, Editor Graeme.Laurie@ed.ac.uk

\section{REFERENCES}

1 Re B (adult: refusal of medical treatment) [2002] 2 All England Reports 449. 2 Airedale NHS Trust $v$ Bland [1993] 1 All England Reports 821, House of Lords.

3 British Medical Association. Withholding and Withdrawing Life Prolonging Medical Treatment: Guidance for Decision-Making, 2nd edn. London: BMJ

Books, 2001.

4 R (on the application of Burke) v General Medical Council [2004] All England Reports (D) 588.

5 Pretty $v$ United Kingdom [2002] 35 European Human Rights Reports 1. 